\title{
Detection of Perfluorooctane Surfactants in Great Lakes Water
}

Bryan Boulanger ${ }^{1}$, John Vargo $^{2}$, Jerald L. Schnoor ${ }^{1}$, and Keri C. Hornbuckle ${ }^{1} *$

${ }^{1}$ University of Iowa, Department of Civil and Environmental Engineering, SC 4105 Iowa City, IA 52240

${ }^{2}$ University Hygienic Laboratory, 102 Oakdale Campus, Iowa City, IA 52242

* Author to whom correspondence should be sent

email: keri-hornbuckle@uiowa.edu phone: 319.384.0789 Fax: 319.335.5660 

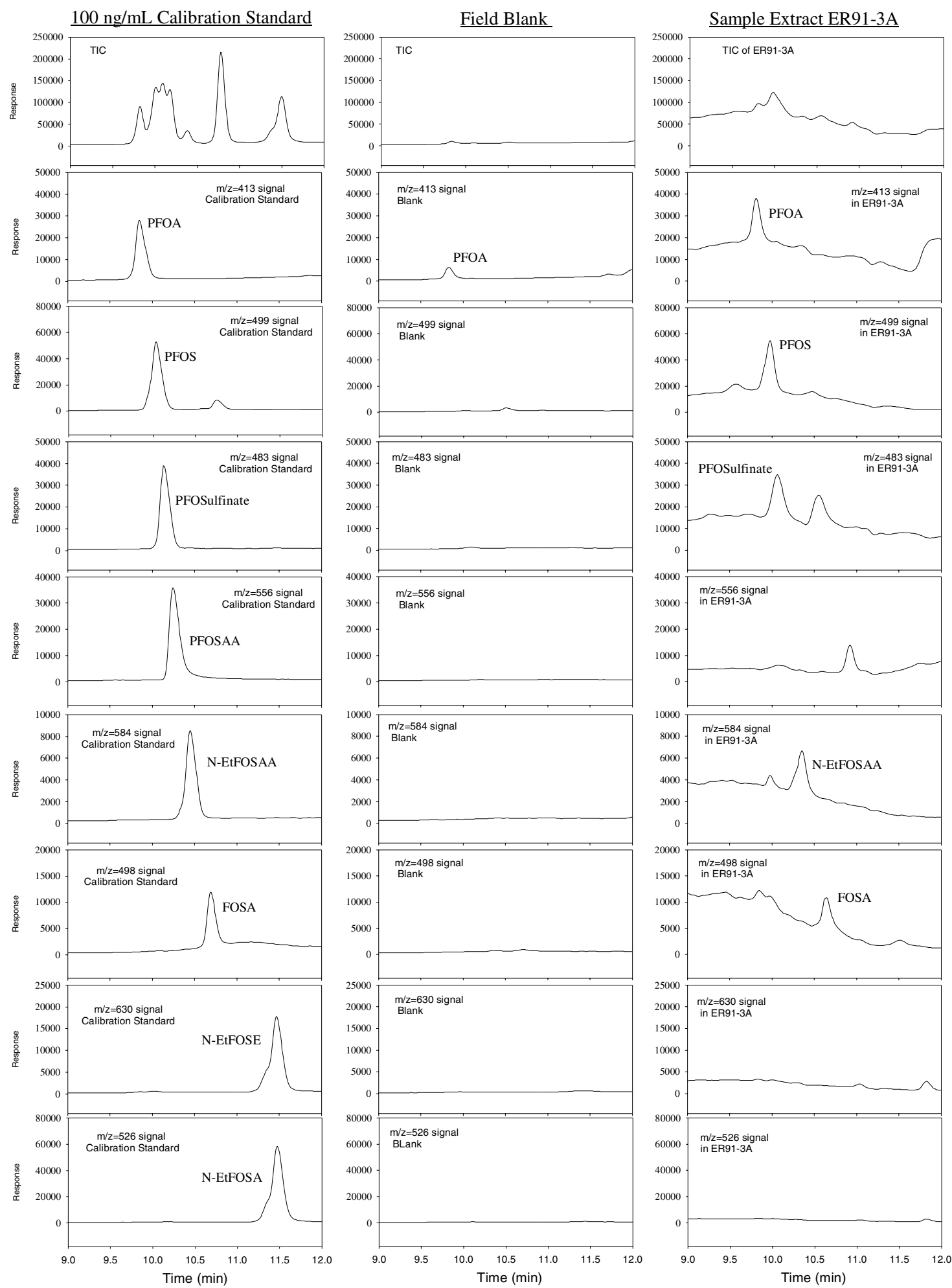

Figure 1. Chromatography of a $100 \mathrm{ng} / \mathrm{mL}$ standard, a blank, and an example extract (ER91-3A) for all analytes. 